\title{
PAROXYSMAL TACHYCARDIA IN A CHILD SHOWING STOKES-ADAM AND WOLFF-PARKINSON-WHITE SYNDROMES
}

\author{
BY \\ STANLEY DE SILVA \\ From the Lady Ridgeway Hospital for Children, Colombo, Ceylon
}

(RECEIVED FOR PUBLICATION JULY 13, 1959)

Paroxysmal tachycardia in infancy may be accompanied, as in the adult, by some disturbance giving rise to pallor, restlessness, dyspnoea, weakness and usually cardiac insufficiency and decompensation. A labile autonomic nervous system makes infants particularly vulnerable to paroxysmal forms of tachycardia. Exactly what it is that starts this disorder or rhythm is frequently obscure and consequently functional autonomic disturbances must often be assumed to be responsible.

The Stokes-Adam syndrome seen in adults in the course of the development of complete heart block is not often seen in children and the case described below, occurring in a child of 2 years during an attack of supra-ventricular paroxysmal tachycardia, is of unusual interest. The symptoms of cardiac insufficiency, more commonly seen in such cases, were conspicuous by their absence in this instance.

\section{Case Report}

A boy (P), aged 2 years and 3 months, was admitted to the Lady Ridgeway Hospital for Children, Colombo, at 9 a.m. on January 14 with a history of 10 to 15 'fits' a day. He had had two fits in the out-patients' department while awaiting admission, each fit lasting one to two minutes. The previous history was that the child was healthy after a normal delivery. There was no illness of any importance before these fits. He had had similar fits when 8 months old for four days, each fit lasting about a minute, and there were four to five fits each day. A similar attack of fits occurred three months later when the child was admitted to this hospital for a few days. He was discharged and had been admitted again subsequently to this hospital and to a branch hospital at Ragama. Each time he was discharged after a few days with a diagnosis of fits due to round worms and, on one occasion, epilepsy. The mother stated that the fits were not associated with any fever. The child became semiconscious for a few seconds before the fit, and appeared to be quite normal afterwards.

On examination at about 9.30 a.m. the child appeared to be a healthy well-fed boy weighing $22 \mathrm{lb}$. $(9 \cdot 98 \mathrm{~kg}$.).
There were slight pulsations over the veins in the neck. The heart was within normal limits and there were no murmurs. The rate was very rapid-about 220 per minute-and the pulse was regular and very small in volume and tension. There was no cyanosis nor dyspnoea and the child was seated on the bed.

The skin turgor was normal and the fontanelles were closed. There was no spasticity of the limbs or neck. The cranial nerves were normal. The abdomen was soft and there were no masses palpable. The liver and spleen were not palpable. While this examination was going on the child quite suddenly became very pale and fell back on the bed in a faint. He remained so for about 30 seconds. He next had a convulsive fit involving both limbs, lasting about one and a half minutes, and soon regained consciousness; he then appeared to be quite normal in colour and behaviour. It was noticed that during the faint there were missed beats and the heart rate was very slow, about 60 to 64 per minute. The child sat up in bed a few minutes later and seemed to be quite normal and unconcerned with what had happened a few minutes earlier. The heart rate was now very rapid and rose to 140 and later 200 per minute. An electrocardiogram was taken soon after and proved very interesting, as the child had a similar faint and fit while this record was being taken. In fact the record was interrupted during the fit for a minute or so. The recording proved an interesting study. Fig. 1 shows a paroxysmal tachycardia of the supra-ventricular type at a very rapid rate of 260-270 per minute. There are short periods of complete cardiac-standstill varying from 0.6 to $0.8 \mathrm{sec}$. It was noticed that the child fainted off during this period of asystole and when he recovered a few moments later the rhythm was slow and irregular at first but later was quite regular and rapid and soon reached a rate of 240 per minute. While the E.C.G. was being examined the child had a similar faint and fit and appeared to be quite normal soon after the fit. He was treated with a sedative syrup of chloral (gr. 3 in 1 drachm) 6-hourly and Tab. Digoxin $0.25 \mathrm{mg}$. 4-hourly from $10 \mathrm{a} . \mathrm{m}$. The pulse rate continued to be over 200 for 24 hours, but 12 hours later it slowed down as shown in the table.

The child continued to have fainting attacks and short 


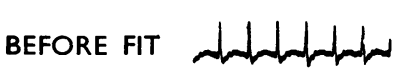

L. I

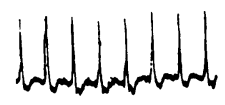

L. II

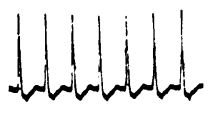

L. III

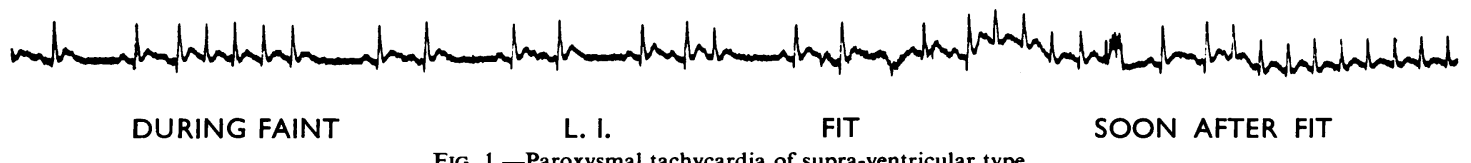

FIG. 1.-Paroxysmal tachycardia of supra-ventricular type.

WOLFF-PARKINSON-WHITE SYNDROME

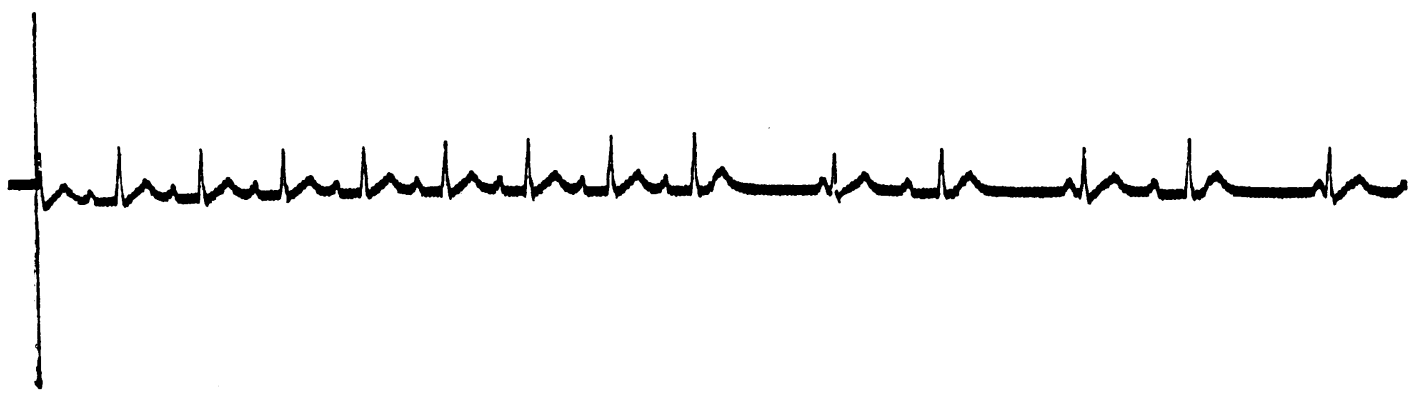

L. I

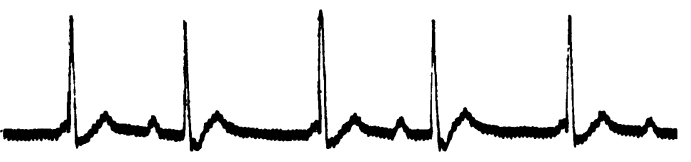

L. II

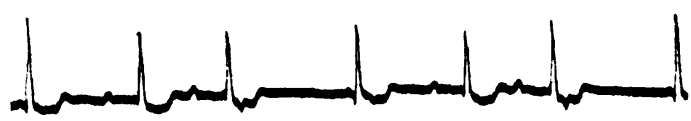

L. III

FIG. 2.-E.C.G. taken after discontinuing Digoxin.

fits about three or four times during this period but was generally comfortable and playing in bed.

On January 17, after discontinuing the Digoxin, another electrocardiogram was taken (Fig. 2). It is seen that Lead 1 starts off with eight normal beats but the ninth is absent while the PR interval of the tenth beat is $0.08 \mathrm{sec}$. This part of the record shows that every

TABLE

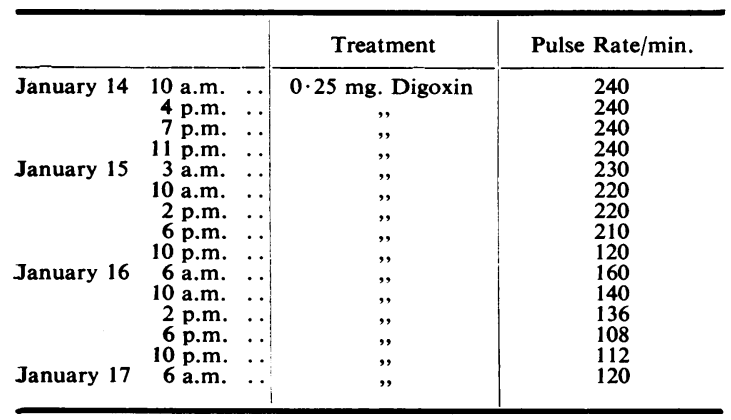

second or third beat has a short PR interval and that each of these beats is preceded by a dropped beat. The shortened PR interval varies from 0.02-0.08 $\mathrm{sec}$. (the normal in infants being not less than $0.12 \mathrm{sec}$.). The QRS complex is widened $0.11 \mathrm{sec}$. with slurring of the upstroke of the $R$ wave (the normal in infancy being 0.05 to $0.06 \mathrm{sec}$.). There are therefore on this record complexes of the Wolff-Parkinson-White syndrome type, each being preceded by a dropped beat. The slurring and widening of the QRS complex with short $P$ waves indicates the presence of the Wolff-Parkinson-White syndrome without any doubt. The E.C.G. records on January 23 (Fig. 3) and February 17 (Fig. 4) showed a
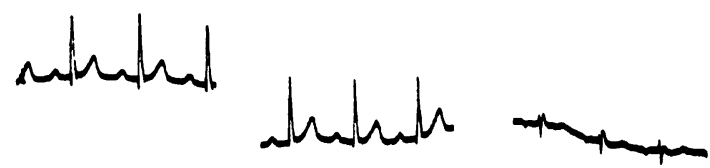

L. I

L. II

L. III

FIG. 3.-E.C.G. showing normal picture with normal rhythm one week later. 

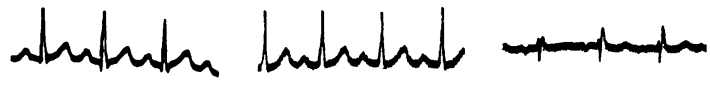

L. 1

L. II

L. III
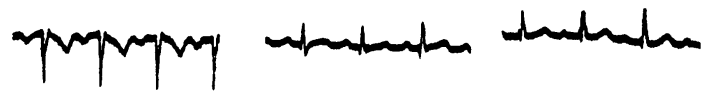

$$
\text { AVR }
$$

AVL

AVF

FiG. 4.-E.C.G. showing normal picture with normal rhythm one month later.

normal picture with normal rhythm. On January 26 the child had two short fainting attacks without any convulsions and Digoxin was given again for four days. The child had another faint on February 2 and on February 17, after being quite well and happy, he left us. A follow-up two years later showed the child to be in good health, with a heart normal in rhythm and rate.

\section{Comment}

The case recorded is that of a 2-year-old child who had a paroxysmal tachycardia of the supra- ventricular type and showed fainting attacks followed by fits very similar to the Stokes-Adam syndrome seen in adults with heart block. A further interesting feature was that on recovering the child showed the presence of the Wolff-Parkinson-White syndrome in the electrocardiogram. This latter syndrome is an electrocardiographic entity and has been the subject of much discussion and study since it was originally described by Wolff, Parkinson and White (1930). Gleckler and Lay (1952) have described the Wolff-Parkinson-White syndrome in a 4-month-old infant with paroxysmal tachycardia in whom an electrocardiogram made on cessation of the arrhythmia showed the presence of the syndrome. The interest in this case is that, besides the Wolff-Parkinson-White syndrome, this child also showed the presence of Stokes-Adam while in hospital.

\section{REFERENCES}

Gleckler, W. J. and Lay, J. V. M. (1952). Wolff-Parkinson-White syndrome and paroxysmal tachycardia in infancy. Report of a case. J. Amer. med. Ass., 150, 683 .

Wolff, L. Parkinson, J. and White, P. D. (1930). Bundle-branch block with short $P-R$ interval in healthy young people prone to paroxysmal tachycardia. Amer. Heart J., 5, 685 . 